\title{
Brief communication "Seismic and acoustic-gravity signals from the source of the 2004 Indian Ocean Tsunami”,
}

\author{
A. Raveloson ${ }^{1}$, R. Wang ${ }^{1}$, R. Kind ${ }^{1,2}$, L. Ceranna ${ }^{3}$, and X. Yuan ${ }^{1}$ \\ ${ }^{1}$ Deutsches GeoForschungsZentrum GFZ, 14473 Potsdam, Germany \\ ${ }^{2}$ Freie Universität, Institut für Geologische Wissenschaften, 12249 Berlin, Germany \\ ${ }^{3}$ Bundesanstalt für Geowissenschaften \& Rohstoffe, 30655 Hannover, Germany \\ Correspondence to: R. Kind (kind@gfz-potsdam.de)
}

Received: 7 September 2011 - Revised: 16 November 2011 - Accepted: 13 December 2011 - Published: 9 February 2012

\begin{abstract}
The great Sumatra-Andaman earthquake of 26 December 2004 caused seismic waves propagating through the solid Earth, tsunami waves propagating through the ocean and infrasound or acoustic-gravity waves propagating through the atmosphere. Since the infrasound wave travels faster than its associated tsunami, it is for warning purposes very intriguing to study the possibility of infrasound generation directly at the earthquake source. Garces et al. (2005) and Le Pichon et al. (2005) emphasized that infrasound was generated by mountainous islands near the epicenter and by tsunami propagation along the continental shelf to the Bay of Bengal. Mikumo et al. (2008) concluded from the analysis of travel times and amplitudes of first arriving acoustic-gravity waves with periods of about 400-700 s that these waves are caused by coseismic motion of the sea surface mainly to the west of the Nicobar islands in the open seas. We reanalyzed the acoustic-gravity waves and corrected the first arrival times of Mikumo et al. (2008) by up to $20 \mathrm{~min}$. We found the source of the first arriving acoustic-gravity wave about $300 \mathrm{~km}$ to the north of the US Geological Survey earthquake epicenter. This confirms the result of Mikumo et al. (2008) that sea level changes at the earthquake source cause long period acoustic-gravity waves, which indicate that a tsunami was generated. Therefore, a denser local network of infrasound stations may be helpful for tsunami warnings, not only for very large earthquakes.
\end{abstract}

\section{Introduction}

Tsunamis are long period gravity waves in the sea caused by vertical displacements of large quantities of seawater. For example, for the great Sumatra-Andaman earthquake of $26 \mathrm{De}-$ cember 2004, a vertical displacement of the seafloor of up to $10 \mathrm{~m}$ was estimated (Bilham et al., 2005; Ji, 2005; Fine et al., 2005; Song et al., 2005 or Heki et al., 2006). The rupture area extended over about $1500 \times 200 \mathrm{~km}^{2}$. The resulting vertical displacement of huge masses of water caused a catastrophic tsunami flooding many shores of the Indian Ocean. Tsunamis are an oceanographic phenomenon and they are traditionally monitored with tide gauges or by sea floor pressure recorders (e.g. DART). The great SumatraAndaman tsunami has also been recorded by satellites, which might be a promising future perspective (Fujii and Satake, 2007). However, it may also be possible to use ocean island and coastal stations of the global seismic network for direct tsunami observations. Nearly a century ago, Angenheister (1920) pointed out that on Samoa at the arrival time of the tsunami of the 17 September 1918 Kurils earthquake, a signal was observed on the horizontal components at the seismic station Apia. Yuan et al. (2005), Hanson and Bowman (2005) and Okal (2007) observed clear effects of the SumatraAndaman tsunami in seismic data. Very similar effects of acoustic-gravity waves on seismic records are known. For example, Müller and Zürn (1983) report about accelerometer signals observed in Germany caused by pressure changes of about $10 \mathrm{~Pa}$ with periods of about $200 \mathrm{~s}$ due to the Mount St. Helens eruption. Atmospheric pressure records are used to reduce seismic noise (Neumann and Zürn, 1999). 

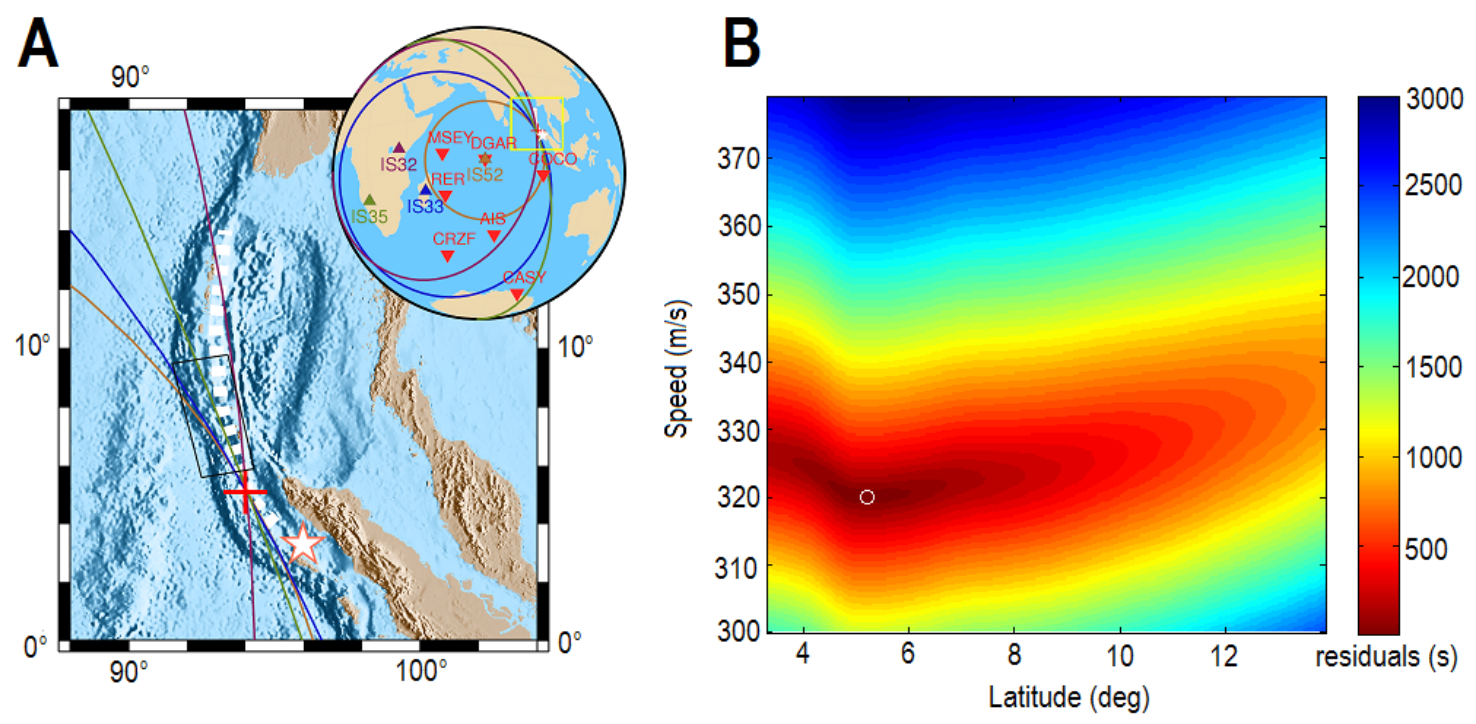

Fig. 1. (A) Seismic stations are indicated by red inverted triangles in the inset. Infrasound stations are represented by color coded triangles. The star marks the earthquake epicenter and the white dashed line represents the earthquake rupture track. The red plus sign represents the location of the source of the first arriving infrasound signals at the infrasound stations. The resulting best fitting parameters are: sound velocity $320 \mathrm{~m} \mathrm{~s}^{-1}$, epicenter at $5^{\circ} \mathrm{N}$ and $94^{\circ} \mathrm{E}$, origin time 01:00:37 UT. This tsunami origin time is $108 \mathrm{~s}$ after the earthquake origin time determined by the USGS. The earthquake rupture reached the tsunami epicenter after propagating with a rupture speed of $2.6 \mathrm{~km} \mathrm{~s}^{-1}$ (Lay et al., 2005) for $108 \mathrm{~s}$. The circles mark the possible source location according to the infrasound travel time to each station. The infrasound epicenter is located at the intersection of all circles. The infrasound source region of Mikumo et al. (2008) is marked by the box north of our epicenter. (B) Travel time residuals as a function of two parameters: the sound speed and the latitude along the rupture track (white dashed line in $\mathbf{A})$.

Vertical displacements of the Earth's surface, sea or land, can cause infrasound or acoustic-gravity waves in the atmosphere. There are reports of observations of such waves caused by the Sumatra-Andaman tsunami. LePichon et al. (2005) and Mikumo et al. (2008) used infrasound arrays of the International Monitoring System (IMS, http://www. ctbto.org/) and barograph stations in Japan for such observations. LePichon et al. (2005) located the source of their first arriving infrasound observations (dominant period $\sim 50 \mathrm{~s}$ ) in the epicentral region of the earthquake. They also identified in the later parts of the records signals originating even from the northern part of the Bay of Bengal. Mikumo et al. (2008) identified $500 \mathrm{~s}$ acoustic-gravity waves caused by swelling and depression of the sea surface and travelling with a speed of about $300 \mathrm{~m} \mathrm{~s}^{-1}$. They used waveform modeling for determining the region of largest displacements of the seafloor. Heki et al. (2006) used GPS data to observe ionospheric disturbances caused by acoustic-gravity waves from the tsunami source region for estimations of the vertical displacement of the surface of the sea. Over half a century ago, Bolt (1964) observed dispersive acoustic-gravity waves from the great 1964 Alaska earthquake at the Berkeley station with periods of about $10 \mathrm{~min}$ and a velocity of about $310 \mathrm{~m} \mathrm{~s}^{-1}$. He suggested using such observations for tsunami warnings. Mikumo (1968) reported additional barograph observations of the same earthquake and modeled their dispersion curves based on a theoretical development by Harkrider (1964). There are also many observations of infrasound signal caused by earthquakes that have occurred on land or at volcanoes which are not related to a tsunami (see LePichon et al., 2006; Arrowsmith et al., 2009; Wiens et al., 2005).

\section{Data}

Figure 1a shows the locations of the infrasound arrays and seismic stations used in this study. The seismic stations belong to the IRIS and GEOSCOPE networks, and the infrasound arrays to the IMS, Vienna. Each infrasound array consists of four to eight array elements with an aperture of about $2 \mathrm{~km}$. In our study, ultra long-period data of the array elements have been summed into a single trace without any time shifts to improve the signal-to-noise ratio.

The star in Fig. 1a shows the epicenter of the great Sumatra-Andaman earthquake of 26 December 2004 (according to the US Geological Survey). The rupture propagation is indicated by a white dashed line. The location of the infrasound source was found by a grid search technique over an area of $10 \times 10$ degrees with the infrasound speed, the source coordinates and tsunami origin time as free parameters. As an example, we display in Fig. 1b the travel time residuals using the latitude of the rupture track 

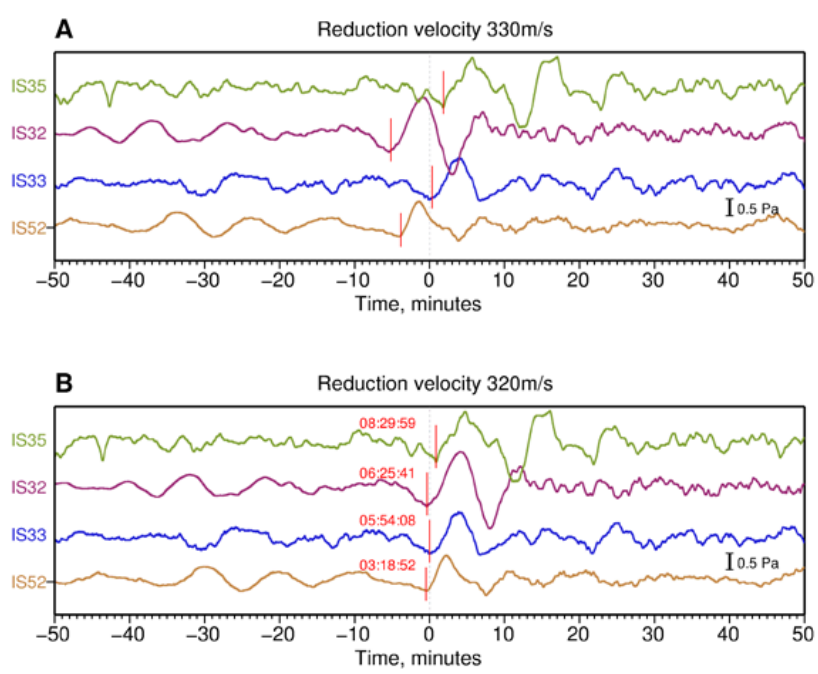

Fig. 2. Summed infrasound records of the first arriving signal from the tsunami at each of the four infrasound arrays. The traces are filtered with a $800 \mathrm{~s}$ high pass filter. (A) Tsunami source is assumed at earthquake epicenter and origin time. Traces are shifted according to a reduction velocity of $330 \mathrm{~m} \mathrm{~s}^{-1}$ (meaning a wave travelling with this velocity would arrive at zero time). The average infrasound speed to each station is close to $330 \mathrm{~m} \mathrm{~s}^{-1}$, assuming the earthquake epicenter also as infrasound epicenter. (B) Tsunami source parameters and infrasound velocity are taken from the caption of Fig. 1. Infrasound first arrival times are given at the traces. The scatter of the wave forms in (B) is clearly less than in (A). That means our epicenter and origin time fit the infrasound data better than the earthquake epicenter and origin time.

and wave speed as free location parameters and moving the source along the rupture track. We minimized the differences between observed and predicted arrival times at the four infrasound stations. The best solution was found for an infrasound speed of $320 \mathrm{~m} \mathrm{~s}^{-1}$ and a source location at $5^{\circ} \mathrm{N}$ latitude and $94^{\circ} \mathrm{E}$ longitude (red cross in Fig. 1a). This location coincides with the maximum co-seismic uplift of the seafloor caused by the high-slip asperity in the southern end of the fault, which was ruptured first (e.g. Hoechner et al., 2008). A delay of $108 \mathrm{~s}$ of the tsunami origin time relative to the origin time of the earthquake was obtained. This fits well the rupture velocity of $2.6 \mathrm{~km} \mathrm{~s}^{-1}$ obtained by Lay et al. (2005). Our infrasound source is located about $200 \mathrm{~km}$ to the south of the location by Mikumo et al. (2008), who derived their location from modeling of arrival times and amplitudes of infrasound phases. Their arrival times at stations IS32, IS33 and IS52 are 8, 7 and 20 min later than ours, respectively (see Fig. 2 and Table 1 by Mikumo et al., 2008). Mikumo et al. (2008) observed similar wind speeds in easterly and westerly directions, which indicate that the wind speed was not very influential to the infrasound propagation at the time of the earthquake. In Fig. 2 infrasound waveforms are displayed with time shifts according to different source

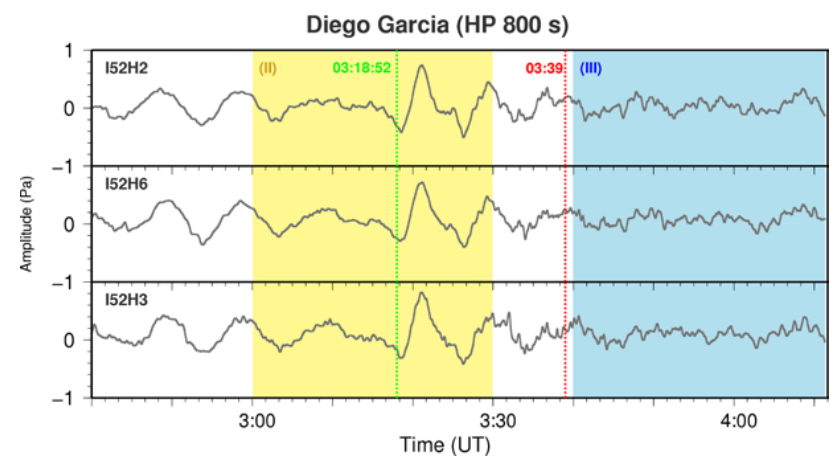

Fig. 3. Infrasound records of the three individual components of the infrasound array at Diego Garcia filtered with a $800 \mathrm{~s}$ high pass filter. Le Pichon et al. (2005) located the source of the signals in group II (yellow) in the extended area of the seismic source. They located the sources of the secondary signals in group III (blue) in the area between Sumatra and the Bay of Bengal. Mikumo et al. (2008) concluded that the first arriving signals were caused by sea level changes in the open sea at the seismic source area. In the case of Diego Garcia, their first arrival time (03:39, see vertical red line) is about $20 \mathrm{~min}$ later than ours (03:18:52, see vertical green line). We compared the infrasound time scale with the seismic time scale at Diego Garcia and found no error in our time determination (see Fig. 4a).

parameters. In Fig. 2a source parameters of the earthquake are used; in Fig. $2 b$ the new source parameters are used. The signals are lined up much closer if the new source parameters are used (Fig. 2b). The arrival times of the first infrasound signal are marked in Fig. 2b. This figure also shows the good signal-to-noise ratio and the great similarity of the infrasound signals at all stations.

Figure 3 shows the records of the individual array components at the infrasound station at Diego Garcia (IS52 and I52). Figure 4 shows the comparison between the seismic (station DGAR) and infrasound (station IS52) records, both on the island of Diego Garcia. There is nearly a one-toone agreement of the waveforms in the first half hour (01:00 to 01:30) between seismic and infrasound traces (Fig. 4a). In principle, the seismogram represents the ground velocity, i.e. the time derivative of displacement, while the infrasound represents the changes in air pressure, which is proportional to the space derivative of displacement of air particles. For propagating seismic waves, there is no difference between the time and space derivatives except for a constant factor. This explains the observed one-to-one agreement of the two waveforms. A ground particle velocity of $1 \mathrm{~cm} \mathrm{~s}^{-1}$ produces an atmospheric pressure change of $5 \mathrm{~Pa}$. Similar observations of coupling from solid Earth to atmosphere have also been made by Watada et al. (2006). They observed a very similar conversion factor. Infrasound in the atmosphere-ionosphere may also be observed with GPS due to the coupling atmosphere-ionosphere (Heki et al., 2006; 

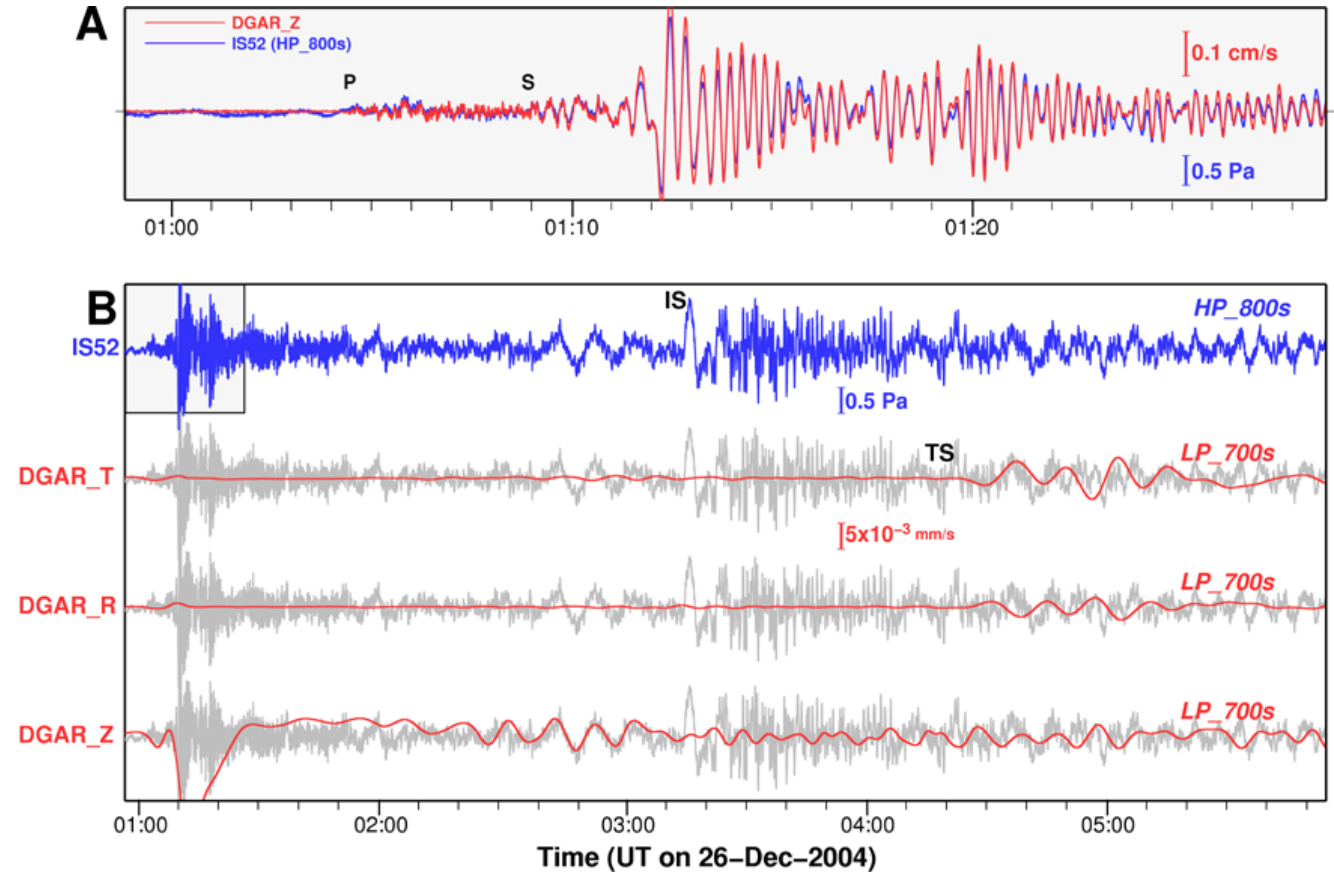

Fig. 4. Comparison of seismic and infrasound records at Diego Garcia. (A) High resolution comparison of seismic (red) and infrasound (blue) records. $P$ and $S$ are seismic body waves; the following large signal is the Rayleigh wave train. There is a nearly perfect agreement of seismic and infrasound records. (B) Filtered ( $\mathrm{LP}=$ low pass, HP $=$ high pass) three-component seismic records (red) and the infrasound record (grey, reproduced from the first record) at the seismic station (DGAR) and the infrasound station (IS52). IS marks the arrival of the infrasound signal and TS the arrival of the tsunami.

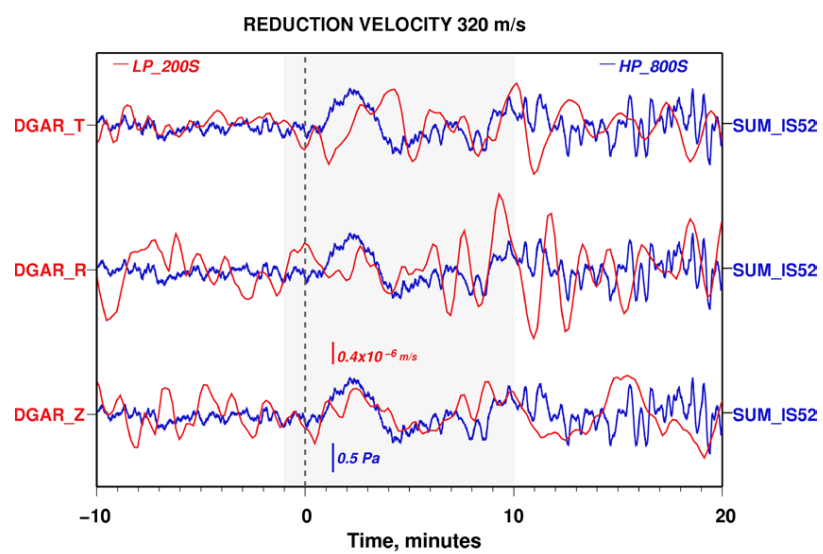

Fig. 5. Comparison of infrasound and three component seismic signals at the arrival time of the infrasound signal at Diego Garcia. The infrasound signals are blue and the seismic signals are red. There are indications of a signal on the seismic $Z$ component at the time of the infrasound signal. There may be also some correlation between seismic transverse component and the infrasound signal, although with some phase shift. The noise level on the radial component is too high to identify an arrival. The question if infrasound can generate measurable seismic signals can only be answered if more data become available.
Artru et al., 2005). Shaking of the barograph by the seismic waves may also contribute to the signals. There is also very good agreement between seismic and infrasound records in the long-period band in the time interval of about 02:30 and $03: 10$, just before the direct infrasound arrival marked IS (see vertical component in Fig. 4b). The relatively strong seismic signal in that time window is located between the direct Rayleigh wave and the one circling in opposite direction around the Earth. The origin of the seismic signal between 02:30 and 03:10 is not clear; it could be some kind of scattered coda wave. The tsunami is well recorded on the longperiod seismic radial and transverse components in Fig. 4b (marked by TS, see Yuan et al., 2005). The TS signals on the horizontal components are caused by tilting of the sea bottom together with the entire island by the tsunami (Yuan et al., 2005; Okal, 2007). It seems that there is some correlation between the waveform of the seismic tsunami record on the horizontal components and the infrasound record. This could indicate that the tsunami might have caused an infrasound signal. However, the evidence for that is not very clear. In order to check if the infrasound arrival has also caused (like the tsunami) a signal on the seismic records, in Fig. 5 we compared the seismic and infrasound records in detail. From comparison with the influence of the tsunami on the seismic records, we might also expect a seismic signal mainly on the 
$\mathbf{A}$
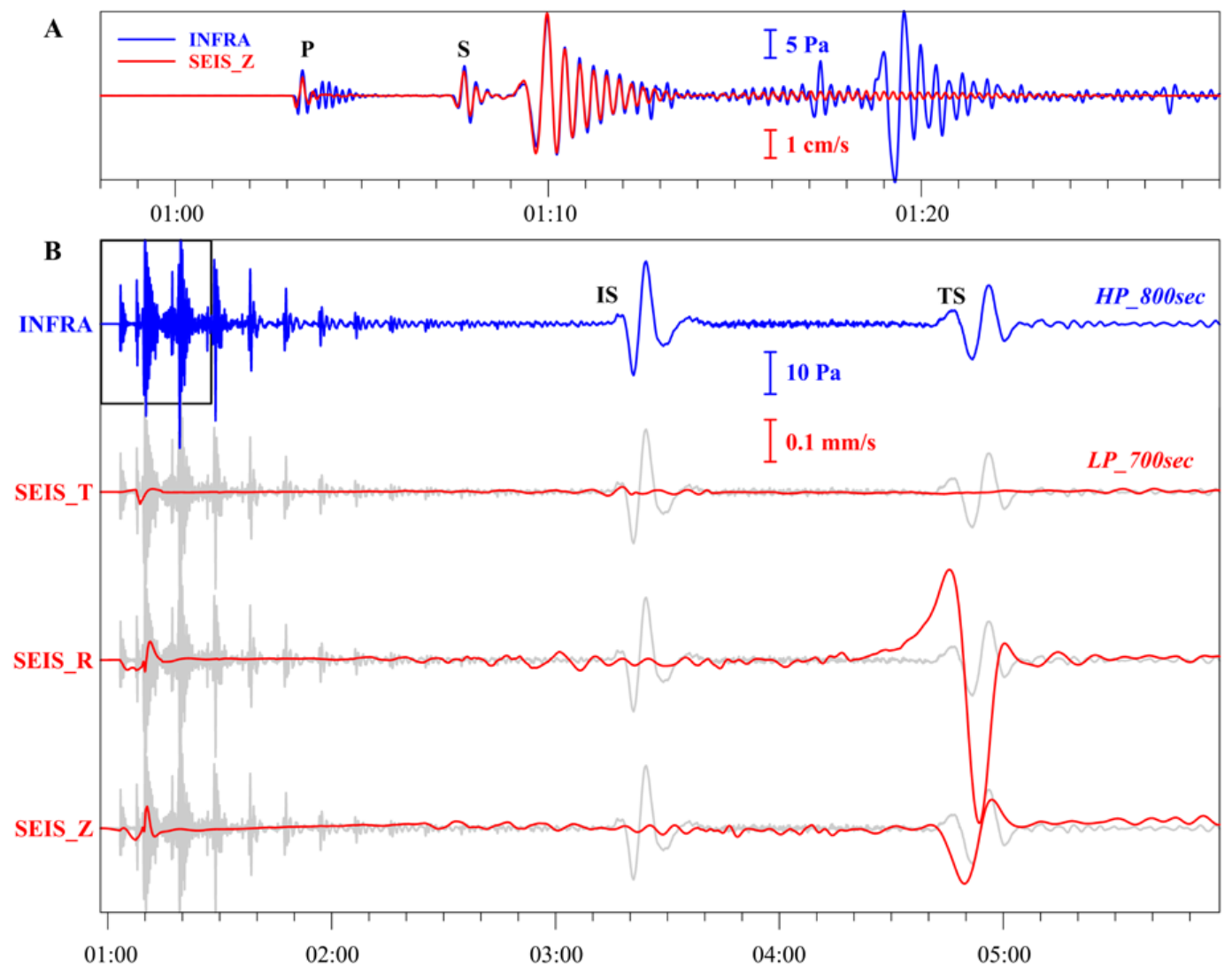

Time (UT on 26-Dec-2004)

Fig. 6. Theoretical infrasound and theoretical seismic traces for the stations at Diego Garcia. (A) Comparison of infrasound (blue) and vertical-component seismogram (red) at higher frequencies within the first $30 \mathrm{~min}$. There is nearly perfect agreement of both types of data up to about 01:17 UT. The ratio of the two traces is $5 \mathrm{~Pa}$ to $1 \mathrm{~cm} \mathrm{~s}^{-1}$, exactly like in the observed data in Fig. 4a. This indicates that the entire infrasound signal in Fig. 4a is indeed caused by leaking of seismic energy into pressure changes in the atmosphere. There is another strong infrasound signal around 01:20 predicted by the model, which is not in the theoretical seismic record. Several more signals of similar type are following (blue trace in B). These signals are probably vertical reflections in the atmosphere that are not propagating horizontally. (B) Comparison of infrasound (blue) and three component (vertical, radial and transverse) long period filtered seismic signals.

horizontal components. There might be in Fig. 5 a signal visible on the transverse component, although with a phase shift. No signal above noise level is visible on the radial component. However, there is a good coherence between the vertical seismic component and the infrasound arrival. Figure 5 shows that the infrasound signal from the source of the Sumatra-Andaman tsunami did not cause a clear effect on the seismic records at Diego Garcia. The observed weak correlation could be due to a random seismic signal. However, Müller and Zürn (1983) observed a seismic signal caused by the about 10 times stronger atmospheric signal of the Mount St. Helens eruption at a station in Germany. Other reports of atmospheric pressure changes in relation to seismic recordings are discussed by Kanamori et al. (1991), Zürn and Widmer (1995), Neumann and Zürn (1999) and Zürn et al. (2005). Therefore, seismic stations closer to the tsunami source might have a chance to record seismic effects of the passing infrasound.
Figure 6 shows theoretical seismic and infrasound traces. The synthetics are calculated using a self-developed code based on normal mode theory (Gilbert and Backus, 1968; Takeuchi and Saito, 1972) and the orthonormalized matrix algorithm of Wang (1999) for numerical stability. The seismic reference model PREM is used for the computations. For a better fitting to the tsunami propagation velocity in the Indian Ocean, we changed the thickness of ocean layer in the original PREM model from 3 to $4 \mathrm{~km}$. Also, a standard atmosphere was added (US Standard Atmosphere, 1976). The entire model is spherically symmetric. Tilt effects due to gravitational tsunami loading are included in the calculation of seismic synthetics, but no instrument effect is included. A point source with the moment tensor determined by the US Geological Survey was used. The theoretical seismic and infrasound records up to 01:17 UT agree very well (Fig. 6a). After that time we obtain strong infrasound signals but no according seismic signal. However, there is still very good 


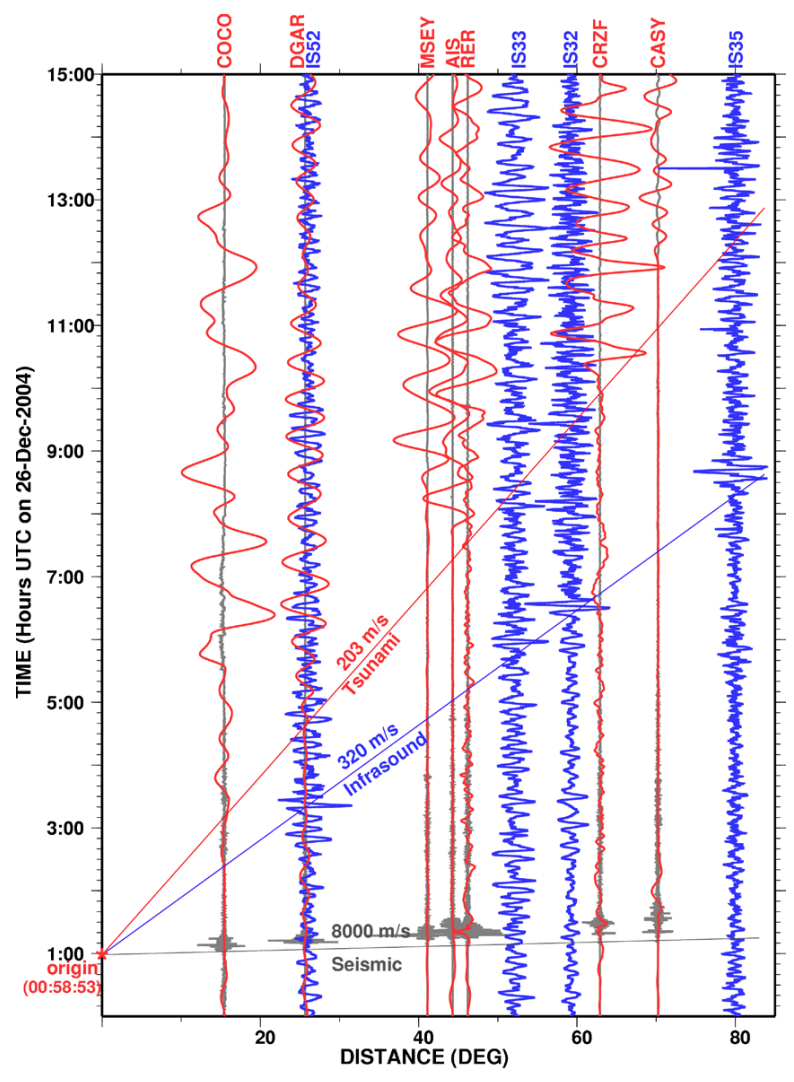

Fig. 7. Seismic and infrasound records of the Sumatra-Andaman earthquake of 26 December 2004 sorted by epicentral distance of the stations. Original unfiltered seismic broadband records are black; long period filtered (E-W component, $1500 \mathrm{~s}$ low pass) seismic records are red; long period filtered ( $500 \mathrm{~s}$ lowpass) infrasound data are blue. Straight lines with velocity indications for the different wave types are also given.

agreement between seismic and infrasound signals in the observed data in Fig. 4a at around 01:20 UT. This is very likely caused by the large spatial extension and time duration of the real earthquake source (see e.g. Lorito et al., 2010) compared to the point source, which we used here for computations. We interpret the computed infrasound signal near 01:20 UT in Fig. 6a, which has even larger amplitude than the first one, as a standing wave (not propagating laterally) in the atmosphere being caused by the arriving seismic surface waves and being reflected between the Earth's surface and the free surface at the top of the upper atmosphere. It is known that the reflection causes the amplitude doubling of the infrasound signal near the surface. Differences between the real Earth and our model are certainly the reason why the signal at 01:20 in the theoretical traces is not clearly visible in the data in Fig. 4. Heterogeneities in the atmosphere are likely an important effect not included in the computations. In order to keep the atmospheric reverberations small, we used a quality factor $Q$ of 100 . This $Q$ factor must not be understood as the intrinsic $Q$ caused by friction. The realistic
$Q$ in the atmosphere is an order of magnitude larger (Blackstock, 2000). The good agreement in Fig. 6a during the first 17 min between the theoretical seismic and infrasound traces confirms that the coherence in the observed data in Fig. 4a before the infrasound arrival is caused by coupling from solid Earth to atmosphere. Shaking of the barograph by the ground displacement plays no role, since no instrument is included in the computations. It seems very difficult to isolate possible effects of infrasound reverberations in the atmosphere, which are predicted by modeling a 1-D atmosphere, from effects of the extended source around 01:20 and later in the observed data. The infrasound trace in Fig. $6 \mathrm{~b}$ shows also the direct infrasound arrival from the source (marked IS) and a signal cause by the arriving tsunami (marked TS). There is no signal on the transverse component in Fig. $6 \mathrm{~b}$ due to tsunami loading, because of the theoretical point source and the 1-D model.

In Fig. 7 the direct comparison of seismic and infrasound data is shown. Both types of data are displayed as a function of the distance to the earthquake epicenter (US Geological Survey: latitude $3.30^{\circ} \mathrm{N}$, longitude $95.98^{\circ} \mathrm{E}, 26 \mathrm{DEC} 2004$, 00:58:53.45). The relatively slight difference in the location of the epicenter of the earthquake and the source of the infrasound signal is not considered in this figure. The seismic data show clearly a wave traveling with a velocity of about $203 \mathrm{~m} \mathrm{~s}^{-1}$, which is a tsunami velocity. These waves have been observed by Yuan et al. (2005) and interpreted as the effect of tilted ocean islands or ocean shores caused by the tsunami (even much smaller tsunamis from landslides have been observed in seismic records, La Rocca et al., 2004). The infrasound data show a phase travelling with a velocity of about $320 \mathrm{~m} \mathrm{~s}^{-1}$. The usual seismic phases are travelling with much faster velocity.

\section{Discussion and conclusions}

We have confirmed that ultra long-period acoustic-gravity signals are detected which originate from the region of the earthquake epicenter. Infrasound signals in front of the direct signal from the source are caused by passing seismic phases, which also produce infrasound. They are easily identified due to their very good coherence with seismic signals. If the infrasound epicenter is located in an oceanic region, we can conclude that the sea level has changed significantly, which means that a tsunami was generated. A subsequent step would be the fast estimate of the size of the sea level changes from infrasound amplitudes (Watada, 2009). Therefore, such infrasound signals may be used for tsunami early warning purposes. Although our infrasound signals have been caused by a very large earthquake, it seems likely that the method can be extended to smaller earthquakes, if a dense network of infrasound stations is deployed closest to the possible earthquake source. 
Acknowledgements. We wish to thank Emile Okal for pointing out the Angenheister observations, Frederik Tilmann for reading the manuscript and for discussions and S. Watada and T. Mikumo for comments. This research was supported by the GITEWS project of the German Federal Ministry for Education and Research and by the United Nations University, Bonn.

Edited by: S. Tinti

Reviewed by: two anonymous referees

\section{References}

Angenheister, G.: Vier Erdbeben und Flutwellen im Pazifischen Ozean, beobachtet am Samoa- Observatorium, 19171919, Nachrichten von der Gesellschaft der Wissenschaften zu Göttingen, 201-204, 1920.

Arrowsmith, S. J., Burlacu, R., Whitaker, R., and Randall, G.: A repeating secondary source of infrasound from the Wells, Nevada, earthquake sequence, Geophys. Res. Lett., 36, L11817, doi:10.1029/2009GL038363, 2009.

Artru, J., Ducic, V., Kanamori, H., Lognonne, Ph., and Murakami, M.: Ionospheric detection of gravity waves induced by tsunamis, Geophys. J. Int. 160, 840-848, doi:10.1111/j.1365246X.2005.02552.x, 2005.

Bilham, R., Engdahl, E. R., Feldl, N., and Satyabala, S. P.: Partial and complete rupture of the Indo-Andaman plate boundary 1847-2004, Seismol. Res. Lett., 76, 299-311, 2005.

Blackstock, D. T.: Fundamentals of physical acoustics, John Wiley \& Sons, New York, 2000.

Bolt, B. A.: Seismic air waves from the great 1964 Alaskan earthquake, Nature, 202, 1095-1096, doi:10.1038/2021095a0, 1964.

Fine, I. V., Rabinovich, A. B., and Thomson, R. E.: The dual source region for the 2004 Sumatra tsunami, Geophys. Res. Lett., 32, L16602, doi:10.1029/2005GL023521, 2005.

Fujii, Y. and Satake, K.: Tsunami Source of the 2004 Sumatra-Andaman Earthquake Inferred from Tide Gauge and Satellite Data, Bull. Seism. Soc. Am., 97, S192-S207, doi:10.1785/0120050613, 2007.

Garces, M., Caron, P., Hetzer, C., Le Pichon, A., Bass, H., Drop, D., and Bhattacharya, J.: Deep infrasound radiated by the Sumatra earthquake and tsunami, EOS Trans. AGU, 86, 317-319, doi:10.1029/2005EO350002, 2005.

Gilbert, F. and Backus, G.: Elastic-gravitational vibrations of a radially stratified sphere, in: Dynamics of Stratified Solids, edited by: Herrmann, G., American Society of Mechanical Engineers, New York, 82-95, 1968.

Hanson, J. A. and Bowman, J. R.: Dispersive and reflected tsunami signals from the 2004 Indian Ocean tsunami observed on hydrophones and seismic stations, Geophys. Res. Lett., 17, L17606, doi:10.1029/2005GL023783, 2005.

Harkrider, D. G.: Theoretical and observed acoustic-gravity waves from explosive sources in the atmosphere, J. Geophys. Res., 69, 5295-5321, doi:10.1029/JZ069i024p05295, 1964.

Heki, K., Otsuka, Y., Choosakul, N., Hemmakorn, N., Komolmis, T., and Maruyama, T.: Detection of ruptures of Andaman fault segments in the 2004 great Sumatra earthquake with coseismic ionospheric disturbances, J. Geophys. Res., 111, B09313, doi:10.1029/2005JB004202, 2006.
Hoechner, A., Babeyko, A. Y., and Sobolev, S. V.: Enhanced GPS inversion technique applied to the 2004 Sumatra earthquake and tsunami, Geophys. Res. Lett., 35, L08310, doi:10.1029/2007GL033133, 2008.

Ji, C.: Magnitude 9.0 earthquake off the west coast of northern Sumatra: Preliminary rupture model, report, US Geol. Surv., Denver, Colo., available at: http://neic.usgs.gov/neis/eqdepot/2004/eq_041226/neic_slav_ff.html (last access: 17 January 2011), 2005.

Kanamori, H., Mori, J., Anderson, D. L., and Heaton, T. H.: Seismic excitation by the space shuttle Columbia, Nature, 349, 781782, 1991.

La Rocca, M., Galluzzo, D., Saccorotti, G., Tinti, S., Cimini, G. B., and Del Pezzo, E.: Seismic signals associated with landslides and with a tsunami at Stromboli volcano, Italy. Bull. Seism. Soc. Am., 94, 1850-1867, 2004.

Lay, T., Kanamori, H., Ammon, C. J., Nettles, M., Ward, S. N., Aster, R. C., Beck, S. L., Bilek, S. L., Brudzinski, M. R., Butler, R., DeShon, H. R., Ekstrom, G., Satake, K., and Sipkin, S.: The great Sumatra-Andaman earthquake of 26 December 2004, Science, 308, 1127-1133, doi:10.1126/science.1112250, 2005.

Le Pichon, A., Herry, P., Mialle, P., Vergoz, J., Brachet, J., Garces, N., Drob, D., and Ceranna, L.: Infrasound associated with 20042005 large Sumatra earthquakes and tsunami, Geophys. Res. Lett., 19, L19802, doi:10.1029/2005GL023893, 2005.

Le Pichon, A., Mialle, P., Guilbert, J., and Vergoz, J.: Multistation infrasonic observations of the Chilean earthquake of 2005 June 13, Geophys. J. Int., 167, 838-844, doi:10.1111/j.1365246X.2006.03190.x, 2006.

Lorito, S., Piatanesi, A., Cannelli, V., Romano, F., and Melini, D.: Kinematics and source zone properties of the 2004 SumatraAndaman earthquake and tsunami: Nonlinear joint inversion of tide gauge, satellite altimetry, and GPS data, J. Geophys. Res., 115, B02304, doi:10.1029/2008JB005974, 2010.

Mikumo, T.: Atmospheric pressure waves and tectonic deformation associated with the Alaskan earthquake of March 28, 1964, J. Geophys. Res., 73, 2009-2025, doi:10.1029/JB073i006p02009, 1968.

Mikumo, T., Shibutani, T., Le Pichon, A., Garces, M., Fee, D., Tsuyuki, T., Watada, S., and Morii, W.: Low-frequency acousticgravity waves from coseismic vertical deformation associated with the 2004 Sumatra-Andaman earthquake (M-w=9.2), J. Geophys. Res. 113, B12402, doi:10.1029/2008JB005710, 2008.

Müller, T. and Zürn, W.: Observation of gravity changes during the passage of cold fronts, J. Geophys., 53, 155-162, 1983.

Neumann, U. and Zürn, W.: Gravity signals from atmospheric waves and their modeling, Bull. Inf. Marees Terr., 131, 10139$10152,1999$.

Okal, E. A.: Seismic records of the 2004 Sumatra and other tsunamis: A quantitative study, Pure Appl. Geophys., 164, 325353, doi:10.1007/s00024-006-0181-4, 2007.

Song, Y. T., Ji, C., Fu, L.-L., Zlotnicki, V., Shum, C. K., Yi, Y., and Hjorleifsdottir, V.: The 26 December 2004 tsunami source estimated from satellite radar altimetry and seismic waves, Geophys. Res. Lett., 32, L20601, doi:10.1029/2005GL023683, 2005.

Takeuchi, H. and Saito, M.: Seismic surface waves, in: Methods in Computational Physics, edited by: Bolt, B. A., Academic Press, New York, 217-295, 1972.

US Standard Atmosphere: US Government Printing Office, Wash- 
ington, DC, 1976.

Wang, R. J.: A simple orthonormalization method for stable and efficient computation of Green's functions, Bull. Seism. Soc. Am., 89, 733-741, 1999.

Watada, S.: Radiation of acoustic and gravity waves and propagation of boundary waves in the stratified fluid from a timevarying bottom boundary, J. Fluid Mech., 627, 361-377, DOI:10.1017/S0022112009005953, 2009.

Watada, S., Kunugi, T., Hirata, K., Sugioka, H., Nishida, K., Sekiguchi, S., Oikawa, J., Tsuji, Y., and Kanamori, H.: Atmospheric pressure change associated with the 2003 Tokachi-Oki earthquake, Geophys. Res. Lett., 33, L24306, doi:10.1029/2006GL027967, 2006.
Wiens, D. A., Pozgay, S. H., Sauter, A. W., and White, R. A.: Tilt recorded by a portable broadband seismograph: The 2003 eruption of Anatahan Volcano, Mariana Islands, Geophys. Res. Lett. 32, L18305, doi:10.1029/2005GL023369, 2005.

Yuan, X. H., Kind, R., and Pedersen, H. A.: Seismic monitoring of the Indian Ocean tsunami, Geophys. Res. Lett., 15, L15308, doi:10.1029/2005GL023464, 2005.

Zürn, W. and Widmer, R.: On noise reduction in vertical seismic records below $2 \mathrm{mHz}$ using local barometric pressure, Geophys. Res. Lett., 22, 3537-3540, 1995.

Zürn, W., Exß, J., Steffen, H., Kroner, C., Jahr, T., and Westerhaus, M.: On reduction of long-period seismic noise using local barometric pressure, Geophys. J. Int., 171, 780-796, doi:10.1111/j.1365-246X.2007.03553.x, 2007. 